useful. That one feels that this is a real shortcoming of the book reflects the rapid pace of progress in this field and the consequent urgent need for up-todate discussion of the ethical issues involved.

ART CONNOLLY Medical Student, Oxford Medical School, Fohn Radcliffe Hospital, Oxford

\section{Law on Poisons, Medicines and Related Substances}

P F C Bayliss, 104 pages, London, Studies in Law and Health Service

Management, Ravenswood

Publications, 2nd ed, 1986

In 1851, the legislature took its first small step in the control of dangerous substances, many of which were then freely available to the public either as constituents in commercially-sold cleansing agents or for pest control, or in themselves as tonics sold for human consumption. The Arsenic Act restricted the use of poison for criminal purposes, an abuse which in the light of recent developments in the illegal use of drugs and medicines generally, has now fallen into insignificance.

The present law on the subject distinguishes between drugs, poisons and medicines, the lines between the different categories being drawn by statutory definition, and not by causal distinctions reached by a layman's common-sense approach. The result has been, for example, that some substances formerly known as poisons have now been absorbed into one or another of the other two categories, with particular regulations applying to the statutory definitions.

The modern law is to be found basically in three statutes passed between the years 1968 and 1972 - the Medicines Act 1968, the Misuse of Drugs Act 1971 and the Poisons Act 1972. As in most enabling legislation, the detailed control of the matters affected lies in the hands of the minister concerned, who issues his directives in the form of statutory instruments which have the force of law, and are subject to the ultimate veto of parliament should they overstep the mark. Finally, the reports of important decisions reached in the High Court provide the precedent on matters not fully defined in the statues, these decisions being binding (for example, the case of $\mathrm{R} \mathrm{V}$ Watts 1984, which is referred to in $\mathrm{Dr}$ Bayliss's book).

One of the most valuable features of the book is the lists of statutes, statutory instruments and cases provided for those who wish to refer to original sources, although adequate summaries may be found in the text. Since the legislation contains the inevitably prosaic minutiae of the administration of dangerous substances, these summaries make hard reading, but this is a book primarily for reference and, as such, is comprehensively done. The people for whom the book is written, namely, anyone working in the health service as a doctor, dentist, pharmacist, midwife or administrator (not forgetting students) cannot be reasonably expected to absorb it all, although it is unfortunately true that a false step taken along the line between factory and patient may incur a penal sanction. It is for those responsible for the administration involving the final destination of a potentially dangerous substance to provide the proper guidance.

For those whom it may concern, then, Dr Bayliss's study explains the nature and purpose of the legislation and summarises the gist of its content. Although much of this is of a pedestrian nature, the writer does not fail to give a degree of prominence to what he considers (rightly) to be the ultimate purpose of the legislation, and he is particularly concerned with the way in which it aims to protect innocent people suffering, or likely to suffer, from the results of any perverted use of the substance in question, for example from the illegal administration of an insufficiently tested drug, or from the illegal use of a drug in order to assist a criminal act such as a rape or an unauthorised abortion.

A proper place is given in the book to the problem of drug addiction, and it appears to the reviewer slightly odd that the word 'drug' does not appear in the title.

The book contains little of direct interest to the ethicist since this was not its purpose, rather it is a clear statement of the law as it stood in 1986.

MRS SHELAGH J GASKILL Solicitor, Dibb Lupton, 6 Butts Court, Leeds LS1 $57 X$

\section{Cross-currents: Interactions between Science and Faith}

Colin A Russell, 272 pages, Leicester, £9.95, Inter-Varsity Press, 1985

The author is Professor of the History of
Science and Technology at the Open University, where he has been involved in the production of three courses related to the theme of this book, which have been taken by several thousand students. So it is not surprising that it is strong on history. Anyone not well acquainted with the theme will profit both from the text and the interesting bibliography. In particular one will learn a good deal of the relation of the scientific achievements to the religious beliefs of great figures of the past from Boyle and Newton to Einstein and Rutherford. Most attention is given to physics. Russell is well aware of the problems of compression, but even so the chapters covering the twentieth century are highly concentrated. After a brief look at Lorenz, Desmond Morris, E $O$ Wilson and Lynn White (the historian) the book rather peters out with a chapter on Faraday.

A mythology has developed on the historical relations between natural science and Christian theology to the effect that it has been a tale of continual warfare between the two, resulting in a series of unsuccessful rearguard actions by theology. Russell has no difficulty in showing that in fact there were varying reactions from both sides. He makes the interesting suggestion that much of the opposition to Darwinism from bot scientists and Christian leaders was because it was perceived to be subversive of the social order, a sociological insight which there is no space to document or follow up.

Russell writes eirenically, but he writes from a type of evangelical theological point of view which requires comment. He wants to vindicate the importance of 'Biblical principles' for the prosecution of natural science, and thus to stress the importance of the Reformation, and to destroy the negative image often attached to Puritanism. (In my view this is because it is treated as too monolithic a phenomenon.) Russell is not a Fundamentalist, as that term is usually understood, the chapter on geology and the Flood makes that clear but, unless $\mathrm{N}$ one accepts a conservative evangelical $N$ theological position, the philosophy and $\mathrm{N}$ theology underlying the book is not $\omega$ satisfactory. It takes no account of the factors of cultural relativity in human 0 thought as a fundamental issue with which modern theology has had to reckon. The Bible is treated as if it speaks in a uniform way. No account is taken of different theologies which have been held at different times related to the same Biblical data. It is not realised $\triangle$ that repeating the same Biblical and $\bar{\sigma}$ 
doctrinal words does not necessarily mean that they are always understood in the same way. One would not guess that the development of the sciences has led to new ways of handling data from the past, from which sacred books could not be exempt, so that a flood of new light has been shed on the Bible. (Officially Islam has not yet come to terms with the same procedures with respect to the Koran, but sooner or later it will have to.)

As instances of what is lacking in this book let us take the work of three major British scholars of our time, James Barr on the Bible, Michael Polanyi on the philosophy of science, and Owen Chadwick on The Secularisation of the European Mind in the Nineteenth Century: none of them has influenced it. Mary Hesse is indeed quoted, but one would not get much idea of the depth of her contribution from what is quoted. Russell's theological comments on the contemporary scene therefore seem somewhat jejune, and his efforts to be fair are taxed at this point. He makes valid criticisms of the simplistic type of scientific positivism, which is by no means dead, but he needs subtler weapons and a greater sense of the reciprocity of the relationship between natural science and Christian theology to do full justice to his theme.

RONALD PRESTON Emeritus Professor of Theology, University of Manchester

\section{Alzheimer's Dementia: Dilemmas in Clinical Research}

Vijaya L Melnick, and Nancy $\mathrm{N}$ Dubler, 312 pages, Clifton, New Jersey, £46.85, Humana Press, 1985

The rationale behind the choice of articles in this collection is obscure. In their introduction the editors imply that the articles emerged from a National Institute of Ageing (NIA) sponsored conference on 'Senile Dementia of the Alzheimer's Type (SDAT) and Related Diseases: Ethical and Legal Issues Related to Informed Consent'. However, whether the book contributors made the same contributions to the conference is not clear. Equally unclear is the background of the contributors. The book lists only their institutions of origin and from this it appears that they are probably predominantly members of the medical and legal professions.

To continue the theme of obscurity it is never clear why the book should concentrate on SDAT when, as the opening chapter points out, this accounts for only 50 per cent of the cases of senile dementia. Contributing to the obliqueness of the book is its general layout which lacks an overall introduction to the ethical issues and a clear statement on why it may be necessary to consider SDAT in isolation. It is not until Part 3 that the 'Historical, Legal and Ethical Background' is considered. The historical perspective presented throughout the book is generally poor, often being merely chronological and not seeking to contextualise. This creates the impression that the legislation on informed consent in the US has functioned to protect the interests of the patient rather than, it appears, to protect medical interests. This naively liberal tone runs throughout the book and generates the suspicion of a hidden agenda which is reinforced by the book's lack of clarity. What constitutes this hidden agenda is, needless to say, unclear.

A question raised early in the book is how can informed consent be obtained from persons whose competence is lacking, questionable or diminishing? Some of the articles do emerge from the general haze of obliquity to attack and go beyond this question, covering the difficult issues of collective control (Andrew Jameton), equity (Harry $\mathbf{R}$ Moody) and proxy consent (Bruce $L$ Miller). These articles are general and removed from some of the parochial concerns of much of the book. Unfortunately little of the book grapples with the limitations of viewing consent as a necessary and sufficient condition for ethical experiments, a point raised by Harry Yeide in his chapter on 'Objectives and Social Structuring'. Nowhere is the issue of the experimentation on marginal groups in the population explored nor the concept of value-free science explicitly questioned.

The parochial nature of many of the chapters limits its relevance to the UK. It must be remembered that the notion of 'informed consent' is a North American concept derived from the decisions of US judges in a series of civil actions since the 1950s. This doctrine is concerned with providing a patient with sufficient information about the intervention to allow him or her to make a rational choice and give true and informed consent (or refusal). This has recently been rejected in the Court of Appeal (and upheld in the House of Lords) as forming no part of British law. Consent to treatment in the UK is based upon a medical standard rather than an autonomous person standard.

However, the position in the UK may be slowly changing. At present there are no legal obligations of consent in the UK. However, the 1983 Mental Health Act brought in new legislation covering consent with certain treatments, psychosurgery for example, requiring consent and a second opinion. The creation of the 1983 MHA was heavily influenced by Larry Gostin who was, significantly, educated in the US legal traditions. The creation of the new Act along with the associated shift from the model of the beneficent doctor to that of the autonomous patient may have future implications for consent outside the realms of psychiatry. Certainly, some of the articles contained in this collection are of value in directing thinking in this area. However, given the nature of the book and its inhibitory cost it may be better to explore the issues in the journals in which the contributors have also outlined their ideas.

DR A P BOARDMAN Lecturer in Psychiatry National Unit for Psychiatric Research and Development, Lewisham Hospital, Lewisham High St, London SE13 6LHC

\section{Law and Morals: Warnock, Gillick and Beyond}

Simon Lee, 98 pages, Oxford, $£ 3.95$ paperback, Oxford University Press, 1986

It may be thought impossible to discuss in any meaningful way the relationship between law and morals in less than 100 pages. Not so, as this volume demonstrates. The book's hallmark is its clarity. There is a concise explanation of the 'law and morals' debate, an exposition of some of the stances which groups take, for example, a Catholic view, a liberal view, the approach taken by Mill (not to do harm to others) and, of course, the Hart/ Devlin debate.

Lee rightly concludes that none of these has a complete answer and he does not presume to provide one. Essentially, his plea is to approach the issues of our time, for example, research on human embryos, surrogacy and contraception by separating differences in relation to predictions and differences which arise from different moral stances. 